\title{
APROXIMACION BIOGRÁFICA A PADRES ADOLESCENTES POBRES: ALGUNAS REFLEXIONES METODOLÓGICAS
}

\author{
BIOGRAPHIC APPROXIMATION TO POOR TEEN PARENTS SOME \\ METHODOLOGICAL REFLEXTIONS
}

\author{
Mónica Solange De Martino Bérmudez ${ }^{1}$ \\ 1 Universidade de la República, Facultad de Ciencias Socieales, Departamento de \\ Trabajo Social, Uruguai, e-mail: monica.demartino@cienciassociales.edu.uy
}

\author{
ARTICLE INFO \\ Article history: \\ Received 2020-01-15 \\ Accepted 2020-04-10 \\ Available online 2020-04-10
}

Palabras-clave: Embarazo. Adolescencia. Biografía. Método Progresivo-Regresivo.

Keywords: Pregnancy. Adolescence. Biography ProgressiveRegressive Method.

RESUMEN. El artículo pretende plantear algunas reflexiones sobre los alcances y límites del método progresivo-regresivo sartreano, a partir de nuestra experiencia de investigación en el campo del embarazo a edades tempranas y estudios sobre masculinidades. A partir de una investigación concreta, se trata de elaborar algunas reflexiones de carácter más general sobre el método sartreano. Todo ello desde la perspectiva del Trabajo Social y, pensamos, extensiva a todas aquellas profesiones asistenciales, esto es, aquellas que se desempeñan en el campo de la asistencia social. Especialmente el artículo se detiene en los desafíos que implica la biografía en términos de encuentro entre dos personas desiguales pero hijas del mismo espíritu de época. Por otra parte, y a los fines de recoger aquellas vertientes marxistas que hacen énfasis en la agencia humana, en las conclusiones se coloca en diálogo al historia Edward Thompson para también problematizar los resultados de las historias de vida realizadas en el marco de la investigación. SI Sartre aporta la dialéctica de lo universal y lo particular, Thompson nos traerá la de conciencia y ser social, ambas de difícil acceso a través de historias de vida.

\begin{abstract}
The article aims to raise some reflections on the scope and limits of the Sartrean progressive-regressive method, based on our research experience in the field of early pregnancy and studies on masculinities. From a concrete investigation, it is about elaborating some reflections of a more general nature about the Sartrean method. All this from the perspective of Social Work and, we think, extensive to all those care professions, that is, those that work in the field of social assistance. Especially the article stops at the challenges that the biography implies in terms of meeting between two unequal people but daughters of the same period spirit. On the other hand, and in order to collect those Marxist aspects that emphasize human agency, in de concluisions Edward Thompson is placed in dialogue to also problematize the results of life stories carried out within the framework of the investigation. If Sartre brings the dialectic of the universal and the particular, Thompson will bring us the conscience and social being, both difficult to access through life stories.
\end{abstract}




\section{Introducción}

Estas reflexiones parten de mi experiencia como investigadora en el campo de la infancia, género y familia. Partimos de una convicción: sostenemos, desde hace tiempo, que la/s concepción/es metodológicas en Trabajo Social se encuentran altamente cosificadas, incluso aquellas que provienen del campo del marxismos. Si bien reconocemos los aportes realizados por diversos autores (IAMAMOTO, 2009; NETTO, 1992) con relación a comprender la profesión desde una perspectiva materialista dialéctica, puntualizamos que tales aportes hacen a una lectura de la profesión y su historia, sin poder avanzar en la aplicación de tal conocimiento para la transformación social. No es voluntad de tales autores, pero la formación del Trabajo Social, incluso en aquellos núcleos académicos identificados con el marxismo, encuentran dificultades a la hora de aprehender la dimensión práctica conocer para transformar - tan sustantiva para el Trabajo Social. Es por ello que, sin negar los aportes de varios núcleos académicos pensamos que resta aún mucho por andar en la formación profesional en términos de investigación y de una práctica profesional teórica, técnica y éticamente sustentada.

Creemos que la formación en Trabajo Social corre el riesgo advertido por Sartre (2004) y Heller (1972) sobre la cosificación de aquellas mediaciones abstractas o determinaciones abstractas fundamentales para comprender un orden social. Cosificación que se reproduce si no encontramos aquellas mediaciones que nos permitan acceder a lo más complejo, es decir, a lo concreto como tal, como síntesis compleja de múltiples determinaciones, en el entendido marxista.

Trabajo Social se enfrenta a múltiples determinaciones y mediaciones que se expresan en problemáticas cotidianas y por veces, consideradas "irrelevantes" por los propios trabajadores sociales. El desafío, para aquellos que formamos a los futuros agentes profesionales, es poder transmitir la capacidad de "hilar" aquellas mediaciones y determinaciones que se expresan en un programa social particular, en una situación grupal específica o en una situación familiar determinada. Poder transmitir la capacidad de comprenderlas como fruto de una época y del espíritu de esa época es un gran desafío.

\section{Fundamentación}

Sartre nos dice: "(Marx estaba) convencido de que los hechos nunca son apariencias aisladas; que si se producen juntos es siempre dentro de la más alta unidad de un todo, en la que están ligados entre sí por relaciones internas y en la que la presencia de uno modifica profundamente al otro" (SARTRE, 2004, p.26). Sartre se encuentra comprometido con la recuperación del individuo, del sujeto, también lo está con otra comprensión o forma de entender la totalidad. En base a lo expresado en la cita anterior, la totalidad, categoría central para Marx, se convierte en una totalidad móvil, una totalidad que se totaliza a sí misma, en permanente movilidad. Y la totalidad es "una filosofía que se convierte en el mundo" 
(SARTRE, 2004, p.30). El autor coloca un ejemplo que nos parece claro teniendo en cuenta que los esfuerzos de Marx para no "forzar" un "universal" a la hora de explicar un "particular". Es decir, no sometía a distorsión ninguna mediación abstracta para alcanzar la comprensión de una situación particular compleja. Veamos el ejemplo colocado por Sartre (2004). Según el autor El 18 Brumario de Luis Bonaparte es un buen ejemplo de cómo Marx intentó comprender el concepto de pequeña burguesía a partir de sus características antes de 1848, pero también teniendo en cuenta su posterior evolución. Es decir, a partir de situaciones concretas observó si era necesario modificar o no la mediación "abstracta". A partir de este ejemplo, Sartre (2004) nos dice que la historia debe ser considerada como totalidad, pero muy especialmente como totalización; es decir, una totalidad que necesita un totalizador para ser totalización. Esto no es un juego de palabras. Para Sartre (2004), el concepto de totalidad abre el camino a posturas que pueden cosificar la propia totalidad, dándole un carácter inerte, inanimado. La totalidad cambia, se complejiza, "crece" y necesita ser reconstituida por el individuo, a partir de la razón dialéctica, que es la que coloca al ser humano en una posición activa frente al mundo y al conocimiento. La totalidad entendida como totalización, implica la propia dinámica dialéctica entre las diversas dimensiones de la realidad e implica el ser humano activo históricamente y activo cognitivamente para comprender y reproducir racionalmente esa totalidad en totalización. La totalidad no sólo por su dinámica intrínseca es totalización, se convierte en ella por la mediación de la razón dialéctica aplicada por el individuo para comprender la realidad. Es a esa totalización en andamiento que deben remitirse los hechos particulares.

El autor reitera en sus textos: "El modo de producción de la vida material domina en general el desarrollo de la vida social, política e intelectual" (SARTRE, 2004, p.31). "He dicho que aceptamos sin reservas las tesis expuestas por Engels en su carta a Marx: "Los Hombres hacen la historia por sí mismos en un medio dado que los condiciona" (SARTRE, 2004, p. 80) Retoma luego a Engels en la siguiente cita:

Los hombres hacen la historia sobre la base de condiciones reales anteriores (entre las cuales hay que contar los caracteres adquiridos, las deformaciones impuestas por el modo de trabajo y de vida, la alienación, etc.) pero son ellos los que la hacen, y no las condiciones anteriores, si no serían los simples vehículos de fuerzas inhumanas que dirigirán a través de ellos el mundo social. Es cierto que estas condiciones existen y que son ellas, sólo ellas, las que pueden dar una dirección y una realidad material a los cambios que se preparan; pero el de la praxis humana las supera conservándolas (SARTRE, 2004, p. 81-82).

He aquí el punto fundamental de encuentro y crítica del existencialismo sartreano y el marxismo: la relación entre universal y particular, a partir del papel dado a los individuos como productos de su época y productores no sólo económicos. El rescate no de lo individual, sino de lo particular; el rescate de la praxis humana, frente al avance de un marxismo reduccionista, empobrecido teóricamente que subordinó la existencia humana a "universales" tomados 
como leyes absolutas: clase, partido, etc. A esto se refiere Ferrarorti $(1991 ; 2005 ; 2007)$ con su auténtica convicción que la Historia de Vida, por ejemplo, es una praxis interactiva (una relación social entre particulares) que permite conocer cómo las clases subalternas viven la estructura social.

\section{Nuestro Proyecto: Algunas precisiones metodológicas}

Esta ponencia deriva de preocupaciones derivadas de la aplicación de historias de vida a adolescentes padres pobres en barrios periféricos montevideanos. El marco de tal aplicación fue el Proyecto de Investigación: Visibilizando la Paternidad Adolescente en Contextos de Pobreza. Tal Proyecto fue financiado por la Comisión Sectorial de Investigaciones Científicas de la Universidad de la República y apuntaba en líneas muy generales a: 1. Identificar y tipologizar las diversas formas de ser hombre/s que se construyen en contextos de pobreza; 2. Identificar los universos simbólicos hegemónicos asociados a la figura del hijo/a. Las presentes reflexiones, derivadas del Proyecto y no asociadas a sus objetivos específicos, giran en torno a las dificultades encontradas a la hora de realizar historias de vida a adolescentes pauperizados. Pueden leerse como preocupaciones teóricometodológicas derivadas del proyecto. De tal manera que se hace necesario, para el lector extranjero, una breve contextualización socio-económica de los chicos entrevistados y el sector social al que pertenecen.

\subsection{Lo Planificado}

Técnicamente la estrategia metodológica se basó en testimonios de vida de varones en contextos de pobreza, cuyas edades oscilan entre los 14 y 24 años. Se combinaron tales testimonios con la aplicación de entrevistas en profundidad a las mujeres-madres de los hijos de los varones entrevistados, como forma de superar una mirada dicotómica de género y tratar de comprender las interacciones entre los miembros de la pareja al respecto. La conformación de la muestra se realizó a partir de los dispositivos institucionales involucrados y remitió al área urbana de la capital, Montevideo. Intentó ser distribuida equitativamente entre ambos sexos (padres/madres) y entre los tramos etarios de los varones padres: 14 - 18 años (adolescencia); 19 -24 años (juventud, habiendo sido padres en la adolescencia). Estuvo conformada por diecinueve adolescentes, hombres y mujeres. Para el cierre de la muestra se tuvo como guía el punto de saturación (OXMAN, 1998). El criterio de selección de la muestra teóricamente se basó en lo que Bourdieu (1990) ha denominado competencia. Indica Bourdieu (1990, p. 57) "se puede aceptar así que son técnicamente competentes los que son socialmente designados como competentes, y basta designar a alguien como competente para imponerle una propensión a adquirir la competencia técnica que funda a su vez la competencia social". Si bien las historias de casos de familias no reemplazan métodos cuantitativos, son el único medio, para nosotros, para acceder a los procesos internos que se 
dan dentro de ellas, así como a las relaciones entre ellas y el medio (OXMAN, 1998) Paralelamente se aplicaron entrevistas en profundidad a agentes tecno-políticos de las instituciones que avalaron el proyecto, en una muestra constituida por treinta y cinco profesionales. Concretamente se entrevistaron a: 1 . equipos técnico/operativos; 2 . agentes tecno-políticos a los efectos de identificar tanto los atributos materiales y simbólicos que atribuyen a aquellos jóvenes y adolescentes así como los modelos explicativos que usualmente se utilizan para analizar la problemática. En resumen, se aplicó la técnica de entrevista - en diversas modalidades - en tres tipos de universos: 1. Jóvenes padres; 2. Madres de sus hijos/as. 3. Técnicos que trabajan en las instituciones que respaldan el presente proyecto. La estrategia es que el proyecto respondió a dos registros de indagación: el problema en sí y cuáles serían las fortalezas y debilidades de los equipos técnicos para trabajar la temática en aras de fomentar procesos de inclusión social.

\subsection{Los Ajustes Realizados.}

Cabe destacar que una vez iniciado el trabajo de campo, nos tropezamos con dos dificultades de diversa índole. Si bien a nivel teórico ya indicamos la invisibilidad de la paternidad adolescente en sendos artículos (DE MARTINO, 2014, 2016), no pensábamos que la misma iba a ser tan contundente a niveles institucionales. Existieron realmente dificultades para ubicar adolescentes que además de padres/madres. Además de la difícil localización de adolescentes, el re - agendar las entrevistas se tornó en algo habitual, transformándose en muchos casos en entrevistas fallidas de acuerdo a la voluntad adolescente. Podemos decir que por cada entrevista realizada, estuvo en una relación de 1.50 contactos fallidos por los temas advertidos por los equipos técnicos (cambios de celulares, de domicilios, fragilidad en los vínculos, etc.) A esto se agregó que, institucionalmente y en general, son las madres las identificadas y con quienes se trabaja. La extrema especialización de algunos programas hace que el padre adolescente sea abordado como estudiante, trabajador, joven en situación de calle, pero no como padre, aunque así lo sea. Primera dificultad: los adolescentes, padres y jóvenes, son invisibilizados en el marco de las políticas públicas. No dicen, no son. A este problema se le sumó una característica de los adolescentes que de alguna manera incidió en la tarea: el limitado manejo del vocabulario, las dificultades en torno a la construcción de un discurso que tenga el yo como protagonista. Sin llegar a realizar una apreciación ontológica del lenguaje, debemos reconocer que las condiciones socio-políticas actuales, caracterizadas por una fuerte segmentación social, por un individualismo acérrimo y por una alta individualización de los problemas sociales, hacen muy difícil que el lenguaje una a los individuos (BAUMAN, 2003). Las condiciones de producción, distribución y consumo de los discursos también son altamente diferenciadas, lo que hace que 
la entrevista encuentre mayores dificultades para su realización. Por tanto, más que historias de vida, se intentó crear espacios de encuentro para la realización de relatos de vida, respetando al entrevistado. Segunda dificultad encontrada: el pauperismo parecería que "separa" de procesos civilizatorios consolidados (comunicación verbal) a contingentes poblaciones que son asociados a los pobres, jóvenes y varones, no solamente. Pero estas dos dificultades constatadas en el mundo material hacen a otra de mayor envergadura y sobre la cual intentamos reflexionar junto a ustedes: ¿Cómo aplicar Historias de Vida cuando el Otro es tan diferente a mí y encarna (particulariza) lo indigno y rechazable de este capitalismo tardío? ¿Cómo entablo relaciones empáticas que me permitan el conocimiento? Sobre esto trata la ponencia en base a nuestra experiencia en el Proyecto.

\subsection{Presentación Breve y Vivencial de los y las Entrevistados/as}

Hemos entrevistado a representantes de la adolescencia más desprotegida, que lleva adelante sus vidas como pueden y de la mejor manera que pueden hacerlo. Podemos indicar que nos hemos acercado, por escasas horas, a las expresiones más duras de la pobreza, algunas de las cuales son apenas atenuadas por programas y servicios sociales que, más allá de objetivos y voluntades, no dejan de ser meramente paliativos. En la muestra no hay ejemplos de adolescentes provenientes de los dispositivos más duros de una protección de la infancia ya caduca. Sí algunos usuarios de servicios relativos al ingreso al mercado de trabajo. Pero dialogando con esta adolescencia pobre, no estamos ante situaciones que transcurren en correccionales o institutos totales. La amplia mayoría de los/las adolescentes estudiaban al momento del embarazo, más allá de hacerlo como "rutina" y sin expectativa en la mayoría de los casos. El centro educativo es un centro de reunión, socialización y de una integración simbólica más que real. Cabe destacar que ninguna de las parejas participó de programas específicos para embarazo en la adolescencia. En general, la adolescencia a la que nos acercamos en el proyecto, viven en barrios de origen obrero, pero sumamente estigmatizados por problemáticas asociadas a la inseguridad, pobreza. Pero viven en las zonas que rodean tales barrios en formas de asentamientos precarios. Otros pertenecen a barrios asociados a fallidas políticas de vivienda, hoy prácticamente edificios abandonados, donde las familias fueron ocupando los apartamentos y tratando de mantenerlos de la mejor manera posible. Pero en definitiva hablamos de barrios periféricos, estigmatizados y que reúnen muy precarias condiciones de existencia. En otras palabras, estos adolescentes y sus parejas portan la identidad de la pobreza, de lo marginal y de lo "desviado". Constituyen casi un estereotipo intelectual y político: niveles educativos que apenas sobrepasan primaria, no estudian, apenas trabajan y si trabajan lo hacen de manera esporádica o en ocupaciones que exigen muy poca calificación o formación, rara vez lo hacen de manera formal. Las adolescentes no trabajan, dedicándose a tareas de cuidado la mayoría de ellas. 
En general estos adolescentes, si viven en pareja, lo hacen en la casa de origen de la adolescente mujer. Solo dos de las parejas viven de manera independiente. Las condiciones habitacionales son absolutamente insuficientes en términos materiales y subjetivos. Las vidas de estos adolescentes, apenas traspasan los límites de sus barrios, es decir, su movilidad social, espacial y cultural es prácticamente nula. Los varones que trabajan de manera formal o continua se desplazan hacia el centro de la ciudad, aunque en algunos casos el trabajo se ubica de manera próxima al domicilio. La vida comienza y acaba en el asentamiento precario. No acceden ni circulan en su zona bienes culturales o simbólicos que hacen la universalidad de la ciudadanía.

\section{Adolescencia/s: Algunas Precisiones Conceptuales}

Los aportes de Havighurst $(1953,1972)$ son considerados pertinentes para abordar este tópico. El autor acuña el concepto de tareas evolutivas y asigna diez a la adolescencia. Una de ellas es construir aquella identidad de la que hablábamos y un self sólido. Si el adolescente se acepta y se quiere, tanto física como emocionalmente, comenzará un camino independiente a partir de las apreciaciones sobre sí mismo que va construyendo. Si encuentra dificultades para aceptarse y para entender sus dilemas, será difícil que desarrolle un concepto de sí claro (KIMMEL y WEINER, 1998). A partir de esta concepción de la adolescencia como el período de búsqueda y construcción de la identidad personal, Erikson (1974) construye el concepto de moratoria psico-social, es decir, la adolescenca como un momento de pausa, de "suspensión", de espera de la adultez entendida como madurez. En esta adolescencia como moratoria psico-social es que se incorporan los elementos de identificación imputados por otros y los adquiridos por el propio individuo (KIMMEL y WEINER; 1998; CRUZAT y ARACENA, 2006).

Pensar la adolescencia o juventud como etapas "previas" al mundo adulto, nos inhabilita a reconocer sus propias complejidades y particulares riquezas como todo punto de inflexión en las trayectorias vitales. Si nos remitimos solamente a esa perspectiva, corremos el riesgo de pensarlas negativamente, como etapas caracterizadas por carencias o "dolencias" si es que nos acotamos, por ejemplo, a la etimología de la palabra adolescencia (adolescer) (BREINBAUER y MADDALENO, 2005; RODRÏGUEZ VIGNOLI, 2014; SILBER y CASTELLS, 2003). Cabe agregar también que toda mediación etaria es siempre relacional y su naturaleza no puede ser pensada de manera esencialista u ontológica (CRIADO, 2005, p. 88). Existe una relación socio-política jerárquica entre las personas pertenecientes a diversos tramos etarios, de tal manera que el mundo infantil, adolescente y juvenil es subalterno al adulto, lo que constituye parte de nuestra cultura y se encuentra ampliamente naturalizado (CRIADO, 2005; 
SILBA 2011). Este adultocentrismo que impregna la vida social y política es colocado en cuestión. Elías (1998) nos muestra cómo la jerarquía etaria naturalizada puede ser cuestionada: “(...) la idea de que el poder de mando incondicional de los padres y la rigurosa obediencia de los hijos, incluso desde el punto de vista de éstos, es la disposición más saludable y fértil, hoy en día despierta sospechas" (ELÍAS,1998, p.418). Para el/la investigador/a, las formas de vivir y pensar asociadas a cada etapa etaria no deben de ser tipos ideales o modelos sociales, por tanto, dividir la vida en etapas sucesivas también es algo meramente ilusorio y a evitar. Así por ejemplo, Silba (2011) indica, para el caso argentino, que el concepto de moratoria social es inaplicable en el entendido que:

\begin{abstract}
...la idea misma que la totalidad de los y las jóvenes cuentan con una etapa entre la niñez y la adultez caracterizada por la posibilidad de aplazar compromisos laborales, maritales, familiares, etc., constituye una reducción de la diversidad de experiencias juveniles, ya que no toma en cuenta en su enfoque las diferencias que representa el cruce de la edad con la clase, egénero, la etnia, la religión ni el lugar de residencia (SILBA, 2001: 232-233)
\end{abstract}

En la misma dirección, Krauskopf (2004) afirma respecto a la juventud, pero que bien puede ser aplicado a otras etapas de la vida.

\begin{abstract}
El tiempo de ser joven identitariamente varía entre estratos, culturas y clases sociales. La mayoría de las personas menores de edad de la región de latinoamericana, que viven en exclusión social, sin invisibilizadas como tales y enfrentan la premura psicosocial en el cumplimiento de responsabilidades supuestamente adultas y con ausencia de oportunidades. Esta premura se intensifica a partir de la pubertad, momento del ciclo vital que parece legitimar su responsabilidad de procurar la subsistencia y aportar a sus familias (KRAUWKOPF, 2004:27)
\end{abstract}

Podríamos pensar que el individuo hijo de la Modernidad ha sido asociado a un hombre, blanco, racional, europeo y propietarios. El resto de los humanos que no asumen ese modelo ideal han sido catalogados por Hall (1996) como sujetos marcados, en el entendido que son pensados respecto a aquel modelo ideal como inferiores o ubicables en un nivel civilizatorio inferior. A estos sujetos marcados refiere Krauskopf (2004) y hacemos referencia nosotros al abordar la vida de adolescentes pobres que además, asumen la responsabilidad de su paternidad. Y si bien se impone el plural para hablar de adolescencia, para respetar sus variaciones de acuerdo a diversas mediaciones (clase, género, raza, etnia, religión), debe reconocerse que es en este período de la vida donde el camino que se recorre es el camino hacia la propia identidad. El ansia de ser independientes abre las puertas a grupos de pares, diversos nucleamientos de iguales y obviamente a la vivencia de la sexualidad coital (PAPALIA y WENDKOS, 1997). En esta fase de la vida tan especial, confusa y rica, debe pensarse cómo acercarnos metodológicamente a ella, ya que como lo indican Cáceres y Escudero (1994) puede ser una experiencia vivida con alegría pero también puede ser una pesadilla e incluso una tragedia.

\title{
5. Historias de Vida de Adolescentes Pobres: Riesgos teórico-metodológicos a superar
}


Más allá de las dificultades operativas encontradas para plasmar una historia de vida, son las dificultades objetivas y subjetivas de vida del sector social al que pertenecen las que se hacen presentes. En palabras de Ferrarotti (1991), el "grupo restringido" o en palabras de Catani (1982) el narrador como unidad objetiva, expresan en su particularidad y en el proceso de singularización que caracterizan su vida, a su clase o sector social, su medio socio-cultural, sus próximos o prójimos y sus remotos o lejanos vínculos. La distancia económico-cultural entre quien observa/entrevista y el narrador genera fuertes ambigüedades, ya que ambos, entrevistado y entrevistados se encuentran en situación biográfica al decir de Maffesoli (2007, p. 232). Situación biográfica (de clase) claramente diferentes. Este es la primer riesgo que debemos superar, para ello traemos a colación el ejemplo dado por Benjamin (2012) respecto a la "virtuosidad de la entropía" en la figura de la prostituta. Detrás de ella, el cuerpo como mercancía, con un valor de cambio y de uso, pero detrás de ella sus clientes. Detrás de estos adolescentes muchas veces están sus abusadores, sus maltratadores, los patrones que le niegan un trabajo por su aspecto físico, por portar "pobreza" en su físico. Y tras sus escasas palabras, sus discursos cortados, sus particulares dialectos está el sistema educativo segmentado y reproductor de las diferencias sociales, expulsor, no habitable ni amigable para los niños/as y adolescentes de la pobreza y el desamparo. Más allá de lo repulsivo detrás de sus historias de vida, obligatoriamente debemos dejarnos invadir por ese sentimiento de empatía y ver a los entrevistados como seres que sintetizan lo injusto de la totalidad en tanto universal. Debemos re- conocerlos pues yo, en situación biográfica, hago parte esa misma totalidad particularizada.

Otro riesgo o desafío es reconocer que estos y estas adolescentes nos obligan a despedirnos de pre-juicios, pre-conceptos, y a navegar esta biografía como interacción, de la que nos habla Ferrarotti (1991). Siguiendo a Ferrarotti (1991), epistemológicamente, estos jóvenes y adolescentes, nos hacen acordar que "cada hombre es una síntesis individualizada de la sociedad". Esto hace que pensemos, junto a nuestros autores de referencia que es posible alcanzar mediante métodos biográficos, el universal concreto, objetivo característico del materialismo histórico-dialéctico. Pero también conocer a estos jóvenes y adolescentes suburbanos es una aventura: es conocer lo desconocido, es tratar de comprender sus palabras. Tal aventura implica conocer lo real, en tanto totalidad, a partir de estas vidas, a veces vivencias, irreductibles, estrictamente arrinconadas en lo particularísimo biográfico.

En tercer lugar cabe preguntarse, ¿qué otra entidad social debemos pensar y "traer" a la relación de entrevista en el caso que tratamos? ¿Qué entidad social singulariza los universales en estos particulares específicos? Hablando de niñez y adolescencia, claro está. Retomamos a Sartre (2004) y su expresión "dejemos entrar a la infancia", como punto de partido del Yo como proyecto, como "salto y fuga" hacia adelante, en un marco estrecho de posibilidades de objetivación en este caso, es decir, con un campo de los posibles (posibles 
yo objetivados en) sumamente reducido. ¿A qué puede aspirar esta adolescencia? ¿Qué se les permite ser? ¿Dónde singularizan lo objetivo en sus primeros pasos? ¿Dónde viven lo universal de las diferencias de clase por primera vez? Retomando el hilo de la cuestión, y el análisis de la vida de Fleubert que realiza el filósofo francés, un acercamiento biográfico debe ser amplio, biografía y época, pero en un espacio altamente importante para la reproducción de la totalidad y olvidado por las ciencias sociales. Nos referimos a la familia, en la que los niños/as, adolescentes y jóvenes, crean y recrean, relativizan, colorean, sus experiencias vitales. Reciben de ella modelos de acción, creencias, saberes comunes y mensajes sobre su propio ser, sobre la valía de ese niño/a o adolescente, que marca el desarrollo de su vida. Si la historia de vida se acerca al universo cotidiano, particular, ordinario, es justo coincidir con Ferrarotti (1991) que el o la investigador/a debe moverse en un campo donde la intencionalidad ideográfica pueda vencer al apaciguamiento de la intencionalidad nomotética que culmine por cuantificar lo cotidiano o lo inesperado e impensable de estas vidas anónimas. Las citas hasta ahora reproducidas de Ferraroti nos indican que esas dos biografías en interacción al momento de la entrevista son dos particularidades que expresan los universales que sintetizan. No son sólo yo y él, sino el tiempo histórico, el espíritu de una época, en interacción cognitiva pero en interacción social y política. Universal y particulares en contacto, mutuo conocimiento y, por qué, en relación de subordinación, donde el otro, en este caso el adolescente, responde al adulto y al universitario. Ferrarotti, en la suma de citas que hemos realizado de su obra, nos hace recordar a Sartre en torno a la idea de que la totalidad debe ser reconstituida por el individuo, en una postura activa, científica e históricamente. ¿Pero qué sucede cuando el Otro es un adolescente paupérrimo, cuya postura activa cognitiva es limitada y sintetiza lo más indigno de la totalidad capitalista tardía? ¿Cómo el científico puede cognitivamente comprender y reproducir racionalmente esa totalidad cuando el otro apenas puede sostener un discurso reflexivo sobre su propio yo? Tal vez, en términos hipotéticos, sea la propuesta sartreana a la que Ferrarotti respeta en su obra, la que nos aporte algunas pistas a partir del concepto de "conocimiento ordinario". El estar convencidos que una persona sintetiza el todo social y que el totalizador (investigador/a en este caso) debe ecuacionar adecuadamente sus condiciones objetivas de vida y su identidad y sensibilidad, hace necesario acercarse cuidadosamente a las emociones, a las apariencias, a lo incluso desdeñable, a lo extraño para mí, a lo raro para mí. Todo lazo social se inscribe necesariamente también en lo emotivo, lo emocional, lo irracional que es en el fondo lo objetivo subjetivizado pero no consciente. En definitiva, reconocer en los "deleszable" del otro, lo "deleznable" del todo social y de mí mismo, ya que ambos, entrevistado y entrevistador, somos particulares de una misma universalidad compartida. También esa invisibilidad del padre pobre adolescente se encuentra relacionada a aspectos de género: la madre es desde el inicio madre "de", mientras que el padre sigue siendo padre "de". He aquí una de las posibles interpretaciones de las dificultades encontradas. Otra es la 
incapacidad de esta adolescencia pobre de construir su identidad y crear un discurso que transmita su yo. Havighurst $(1953,1972)$, ya lo había señalado y ya fue citado ut supra. ¿Cómo entrevistar y encontrar sintonía con quien no ha culminado "las tareas" de la adolescencia, cuya adolescencia no ha sido como la mía, con quien tengo tan pocas condiciones empáticas? Tal sólo a través de la "virtuosidad de la entropía", como ha dicho Benjamin (2012) podamos encontrar los caminos para comprender que ese otro, absolutamente diferente a mí, que es un padre que no asume sus responsabilidades, que roza los caminos de lo ilegal, es una particularidad diferente a mí pero que expresa una misma totalidad o universalidad.

\section{Algunas reflexiones finales}

Como reflexión final colocamos a disposición de los lectores otra preocupación que va más allá de la metodología utilizada sino que hace al análisis de los resultados. Y es nuestra preocupación en torno a cómo conceptualizar la experiencia a esta edad y en contextos absolutamente desprovistos de lo básico. En un contexto histórico de serias disputas teóricas en el movimiento comunista europea, así como entre sus máximos representantes teóricos pos-segunda Guerra Mundial, el historiador Edward Thompson (1981) plasma en varios textos de envergadura su postura frente al estructuralismo francés, acercándose de cierta manera al marxismo existencialista sartreano, en términos de recuperar al individuo hundido en un baño de ácido sulfúrico, al decir, del filósofo francés.

Cabe aclarar que Sartre (2004) no anunciaba la muerte del individuo moderno, ni indicaba posturas posmodernas en torno al tema. Lo que Sartre (2004) quería señalar con esa frase es que el marxismo francés estructuralista había hundido al individuo, a la acción humana, bajo mediaciones universales que ya no tenían "contacto" con el ser humano particular y su singularidad. Para Sartre "la clases social", "el partido" se habían transformado en mediaciones universales formales que ya no retomaban ni permitían analizar la experiencia de hombres y mujeres conformando esa clases y sus luchas. Ese es el sentido dado por Sartre al ser humano muerto con ácido sulfúrico. De ahí su sintonía con Thompson: la necesidad de recuperar las agencias particulares y vincularlas a mediaciones universales. De manera un tanto grosera, podemos indicar que con el concepto de experiencia, el autor inglés intenta comprender y aportar una mirada renovadora, a la relación entre estructura y agencia humana y a la forma de producción del conocimiento en el marco del materialismo históricodialéctico, alejado de todo ismo en torno a la figura de Marx. Pero por sobre todas las cosas, Thompson (1981) trata de desentrañar la relación entre conciencia y ser social; las formas de constreñimiento que el ser social coloca a la consciencia, por decirlo de alguna manera. En ese camino dirá que toda experiencia, es experiencia recuperada, pero no por ello debe ser 
estigmatizada como simple y mero subjetivismo. Como una forma de conocimiento específico, el propio autor se encarga de subrayar sus límites y constatar su validez dentro de los mismos:

En mi opinión la verdad es más matizada: la experiencia es válida y efectiva pero dentro de determinados límites; el campesino "conoce" sus estaciones, el marinero "conoce" sus mares, pero ambos están engañados en temas como la monarquía y cosmología (THOMPSON, 1981, p.19).

Avanzando en su conceptualización, el autor nos indica que la experiencia podría ser entendida como la mediación entre ser social y conciencia social, en sus propias palabras, como el "término medio necesario entre el ser social y la conciencia social", en tal sentido, engarza estructura, cultura, valores, significados y acciones humanas concretas. En clara alusión a Althusser, y tratando de romper la impronta mecánica entre estructura y superestructura, el autor advierte sobre los riesgos de hipervalorar la "determinación" de la vida humana por parte de los aspectos materiales de existencia (estructura). Junto con Williams (1977), entiende que tal determinación puede entenderse como límites o ejercicio de presiones sobre la agencia humana. Debemos agradecer a ambos que tales interpretaciones permitan realizar una crítica severa a la sobredeterminación (de la estructura) que realiza Althusser. Del mismo modo, aunque tal vez sin una precisión teórica absoluta, nos permiten repensar las formas cómo el modo de producción y la estructura de clases se "imprimen" en las acciones humanas y en el modo como la gente vive. En palabras de Sorgentini (2000, p. 57) "Thompson propone la fórmula marxiana "ser social/conciencia social" como alternativa a la dominante en el marxismo "base/superestructura"'. Y esto enriquecería la postura del investigador cuando se acerca a poblaciones o individuos hundidos en el pauperismo, como ha sido nuestra experiencia. En ese entendido el concepto de experiencia puede ser entendido como impreciso. Por un lado aparece determinada por la estructura, pero por otro el autor indica que la experiencia es determinante sobre la conciencia social existente al momento de tal experiencia. A este aspecto ambiguo arremete Anderson (1985), indicando dos sentidos de la experiencia: uno neutro (como trama subjetiva en la que se vivencias los aspectos subjetivos que condicionan la vida social) que él defiende; y otro positivo (como componente de la conciencia social y que expresa las respuestas emocionales y subjetivas de los individuos) que critica por hipersubjetiva y que atribuye a Thompson. Aún en posiciones contrarias, puede decirse que ambos coinciden en recuperar el papel del individuo, de la agencia humana, el punto de vista de los sujetos en la reconstrucción de un período histórico o de un problema socio-político que coloca en jaque valores y significaciones altamente subjetivas, como es el caso de este proyecto.

Es este aspecto el que rescatamos como hilo conductor de nuestra experiencia como entrevistadoras de estos jóvenes. La opinión de estos jóvenes, sus prácticas y juicios, en un campo donde se juegan diversas posturas axiológicas y las mismas carencias materiales, expresan una gama de situaciones que hacen a la clase trabajadora uruguaya respecto a la sexualidad, las relaciones de género y la reproducción biológica y social de la población. Por 
tanto, en estas tramas subjetivas en torno al problema del Proyecto, intentamos leer cómo la experiencia "conjuga" la conciencia y el ser social de estos jóvenes. En palabras de Thompson, "tomaremos sus acciones y sentidos como la huella que dejar el ser social en la conciencia social (Thompson, 1981, p.14). Los resultados no han sido alentadores, al encontrarnos con adolescentes y jóvenes en absoluta soledad y cuyas vidas no nos atrevemos a decir que se caractericen por ser "experiencias" en términos de diálogo con la totalidad.

\section{Referencias}

ANDERSON, Perry. Teoría, política e historia. Un debate con E.P. Thompson. Madrid: Siglo XXI. 1985.

BAUMAN, Zygmunt. Comunidad. En busca de seguridad en un mundo hostil. Madrid: Siglo XXI. 2003,

BENJAMIN, Walter. El país de Baudelaire. Buenos Aires: Eterna Cadencia Editora. 2012.

BOURDIEU, Pierre. Sociología y Cultura. México: Grijalbo.1990.

BREINBAUER, Cecilia; MADDALENO, Matilde. Youth: Choices and change Promoting healthy behaviors in adolescents. Maryland: Pan American Health. 2005.

CÁCERES, José; ESCUDERO, Valentín Relación de pareja en adolescentes y embarazos no deseados. Madrid: Ediciones Pirámides. 1994.

CATANI, Maurizio. Tante Suzanne: une historie de vie sociale. París: Librairie des Méridiens. 1982.

CRIADO, E. Martín. La construcción de los problemas juveniles. Nómades, n. 23, p. 86 $-93,2005$.

CRUZAT, Claudia.; ARACENA, Marcela. Significado de la Paternidad en Adolescentes Varones del Sector Sur - Oriente de Santiago. Psykhe, v. 15, n.1, p. 29-44, 2006.

DE MARTINO, M. Padres adolescentes y jóvenes: debates y tensiones, Katalysis, v. 19, n. 1, p. 91- 99, 2016.

DE MARTINO, M. Visibilizando la Paternidad Adolescente. Prisma Social, n. 13, p. 924 943, 2014.

DE MARTINO, M. Sobre el método progresivo-regresivo sartreano. Aportes teóricometodológicos que rescatan el lugar de la infancia. CONGRESO IBERO AMERICANO DE INVESTIGACIÓN CUALITATIVA, 8, Salamanca. Investigación Cualitativa en Ciencias Sociales, Actas CIAIQ2019, v. 3, p. 12-17, 2019.

DE MARTINO, M. Sobre el método progresivo-regresivo sartreano. Una perspectiva enriquecedora para la formación profesional desde la teoría marxista. CONGRESO INTERNACIONAL DE TRABAJO SOCIAL DE LA RED DE UNIVERSIDADES DEL CONSEJO DE RECTORES DE UNIVERSIDADES CHILENAS (CRUCH), 3, Temuco. Tensiones ético 
políticas de la formación y práctica disciplinar del trabajo social. Rupturas y consensos de las hegemonías en América Latina, 2019. Mimeo.

ELIAS, Norbert. La civilización de los padres. In: ELÍAS, Norbert. La civilización de los padres y otros ensayos. Bogotá: Norma. 1998.

ERIKSON, Erik. Identidad, Juventud y Crisis. Buenos Aires: Paidós. 1974.

FERRAROTTI, Franco. La historia y lo cotidiano. Barcelona: Península. 1991.

FERRARROTI, Franco. Las historias de vida como método. Convergencia, no. 14, p. 14051435, 2007.

FERRAROTTI, Franco. Historias de vida y Ciencias Sociales. Entrevista a Franco Ferrarotti. Perifèria, n.5, p. 1-14, 2005.

HALL, Stuart. Quién necesita identidad?. In: HALL, S. ; du GAY, Paul. (eds). Cuestiones de Identidad Cultural. Buenos Aires: Amorrotur, 1996.

HAVIGHURST, Robert. Human development and education. New York: Green.1953.

HAVIGHURST, Robert. Developmental tasks and education. New York: McKay. 1972.

HELLER, Agnes. Historia y Vida Cotidiana. México: Grijalbo. 1972.

IAMAMOTO, Marilda. Servicio Social en la Contemporaneidad: Trabajo y Formación Profesional. Sao Paulo: Cortez. 2009.

KIMMEL, Douglas; WEINER, Irving. La adolescencia: Una transición del desarrollo. Barcelona: Editorial Ariel. 1988.

KRAUSKOPF, Dina, Comprensión de la Juventud. El ocaso del concepto de moratoria psicosocial. Jóvenes. Revista de estudios sobre juventud , v. 8, n. 21, p. 26-39, 2004.

NETTO, José Paulo. Capitalismo Monopolista y Servicio Social. Sao Paulo: Cortez. 1992. OXMAN, Claudia. La entrevista de investigación en ciencias sociales. Buenos Aires: Eudeba. 1988.

PAPALIA, Diane.; WENDKOS, Sally. Desarrollo humano. Bogotá: McGraw Hill. 1997. RODRIGUEZ VIGNOLI, Jorge. La reproducción en la adolescencia y sus desigualdades en América Latina. Introducción al análisis demográfico con énfasis en el uso de microdatos censales de la ronda de 2010. Santiago de Chile: CEPAL/UNFPA. 2014.

SARTRE, Jean Paul. Cuestiones de Método. In: SARTRE, Jean Paul. Crítica a la Razón Dialéctica. Buenos Aires: Losada. 2004.

SILBA, Malvina. Te tomás un trago de más y te crees Rambo: prácticas, representaciones y sentido común sobre varones jóvenes. In: ELIZALDE, Silvia. (coord.) Jóvenes en cuestión. Configuraciones de género y sexualidad en la cultura. Buenos Aires: Biblos, 2011. SILBER, Tomás; CASTELLS, Paulino.; Guía Práctica de la Salud y Psicología del Adolescente. Barcelona: Planeta. 2003.

SORGENTINI, Hernán.La recuperación de la experiencia histórica: Un comentario sobre E. P. Thompson. Sociohistórica, n.7, p. 53-80, 2000.

WILLIAMS, Raymond. Marxism and literature. Oxford, UK: Oxford University Press. 1977. 